\title{
Düşük sıcaklık koşullarında fosfin fümigasyonunun bazı depolanmışürün zararlısı böcekler üzerine etkisi
}

\section{The effect of phosphine fumigation on some stored product pests at low-temperature conditions}

\author{
Sait ERTÜRK ${ }^{1 *}$ iD , Umut TOPRAK ${ }^{2}$ iD \\ ${ }^{1 *}$ Zirai Mücadele Merkez Araştırma Enstitüsü, Yenimahalle, Ankara, Türkiye \\ ${ }^{2}$ Ankara Üniversitesi Ziraat Fakültesi Bitki koruma Bölümü, Dışkapı, Ankara, Türkiye
}

To cite this article:

Ertürk, S. \& Toprak, U. (2020). Düşük sıcaklık koşullarında fosfin fümigasyonunun bazı depolanmış ürün zararlısı böcekler üzerine etkisi. Harran Tarım ve Gıda Bilimleri Dergisi, 24(2): 204211.

DOI:10.29050/harranziraat.669245

Address for Correspondence: Sait ERTÜRK

e-mail:

saiterturk@gmail.com

Received Date:

02.01 .2020

Accepted Date:

24.02.2020

(C) Copyright 2018 by Harran University Faculty of Agriculture. Available on-line at www.dergipark.gov.tr/harranziraat
Öz

Depolanmış ürün zararlıları ile mücadelede yoğun şekilde sentetik fümigantlar kullanılmaktadır. Kullanılan bu fümigantların içinde fosfin gazı $\left(\mathrm{PH}_{3}\right)$ önemli bir yer tutmaktadır. Bu çalışmada fosfin gazının düşük sıcaklıklarda ki toksik etkisi araştırılmıştır. Bu amaçla Pirinç biti [Sitophilus oryzae Linnaeus, 1763 (Coleoptera: Curculionidae)], Un biti [Tribolium castaneum (Herbst, 1797) (Coleoptera: Tenebrionidae)] ve Kırma biti [Tribolium confusum Jaquelin Du Val, 1868 (Coleoptera: Tenebrionidae)]'nin erginleri 4, 9 ve 24 saatlik uygulama sürelerinde 150,300 ve 600 ppm fosfin gaz konsantrasyonları ile $1^{\circ} \mathrm{C}$ ve $2.5^{\circ} \mathrm{C}^{\prime}$ lik düşük sıcaklık koşularında ölüm oranları araştırılmıştır. Çalışmada $T$. castaneum ve $T$. confusum için 150 ppm dozda 4 saatlik uygulama süresinde ve $1{ }^{\circ} \mathrm{C}$ sıcaklık koşullarında sırasıyla \% 61.06 ve \% 78.15'lik ölüm oranı elde edilmiştir. Buna karşın bu değerde aynı koşularda S. oryzae için \% 0.20'lik ölüm oranı elde edilmiştir. Çalışmalar 2019 yılı Zirai Mücadele Merkez Araştırma Enstitüsü Depolanmış Ürün Zararlıları laboratuvarında yürütülmüştür. Bu çalışma ile düşük sıcaklık altında fosfin gazı toksisitesinin uygulama süresi ve doz artışına paralel olarak arttığı ve her üç böcek türünde de mutlak ölümün sağlandığı ortaya konmuştur.

Anahtar Kelimeler: Depolanmış ürün zararlıları, Fosfin, Düşük sıcaklık, Toksisite

\section{ABSTRACT}

Synthetic fumigants are extensively used for the control of stored product pests. Among these fumigants, phosphine gas $\left(\mathrm{PH}_{3}\right)$ has an important role. In this study, the toxic effect of phosphine gas was investigated at low temperatures. For this purpose, adult stages of Rice weevil [Sitophilus oryzae Linnaeus, 1763 (Coleoptera: Curculionidae)], Red flour beetle [Tribolium castaneum (Herbst, 1797) (Coleoptera: Tenebrionidae)] and Confused flour beetle [Tribolium confusum Jaquelin Du Val, 1868 (Coleoptera: Tenebrionidae)] were exposed to 150,300 and 600 ppm phosphine gas concentrations at 4, 9 and 24 hours and 1 and $2.5^{\circ} \mathrm{C}$ low temperatures. It was obtained that, at $150 \mathrm{ppm}$ dose, 4 hours exposure period and $1{ }^{\circ} \mathrm{C}$ temperature conditions the mortality rates for T. castaneum and $\mathrm{T}$. confusum $61.06 \%$ and $78.15 \%$, respectively. On the other hand, only $0.20 \%$ mortality rate was obtained for $S$. oryzae under the same conditions. The studies were carried out in the stored product pests laboratory of the Plant Protection Central Research Institute in 2019. It was revealed that the mortality rate increases in all three insect species with increasing exposure time and dose under low temperature conditions.

Key Words: Stored product pests, Phosphine, Low temperature, Toxicity 


\section{Giriş}

Böcekler hiç şüphesiz ki dünya üzerinde farklı besin kaynaklarından faydalanabilen, değişik ekolojik koşullara adapte olmuş ve diğer bir çok hayvan türünün sayısından daha fazla tür çeşitliliği gösteren canlı grubudur. Bu böcek gruplarından özellikle depolanmış hububatta zararlı olanlar ürünlerde istenmeyen koku, kızışma, çimlenmede azalma, sekonder fungal ve bakteriyel bulaşmalara yol açmakta ve ürünün ticari değeri ortadan kalkmaktadır (Sallam, 1999). Depolanmış ürün zararlısı böceklerin büyük çoğunluğu Coleoptera ve Lepidoptera takımına bağıı türlerdir (Khare, 1994). Depolanmış ürün zararlıları içerisinde ülkemizde ve dünyada önemli yer tutan özellikle uzun süreli depolanan ürünlerde sorun olarak karşımıza çıkan, pirinç biti [Sitophilus oryzae Linnaeus, 1763 (Coleoptera: Curculionidae)], un biti [Tribolium castaneum (Herbst, 1797) (Coleoptera: Tenebrionidae)] ve kırma biti [Tribolium confusum Jaquelin Du Val, 1868 (Coleoptera: Tenebrionidae)] önemli bir yer tutmaktadır (Bağcı ve ark., 2014). Yapılan çalışmalarda depolanmış ürün zararlısı böcekler ile bulaşık ürünlerdeki kayıp oranlarının \% 100'e kadar ulaştığı görülmektedir (Sallam, 2013). Ülkemizde bu zararlılar ile farklı şekillerde mücadele edilmekle birlikte en yaygın ve sıklıkla kullanılan mücadele metodu kimyasal mücadeledir. Kimyasal mücadelede ise uygulama kolaylığı ve geniş etki spektrumuna sahip olması açısından fümigantlar ön plandadır. Metil bromid birçok alanda kullanılan başarılı bir fümigant olmasına rağmen 1992 yılında Montreal Protokolü ile ozon tabakasını tüketen maddeler sınıfına alınmış ve gelişmiş ülkelerde 2005 yılında kullanımı sonlandırılmıştır (Anonymous, 1998; TEAP, 2000). Ülkemizde ise metil bromid kullanımına 2007 yılında son verilmiş ve sadece taşıma öncesi ve karantina amaçlı uygulamalar dışında kullanımı yasaklanmıştır.

Ülkemizde depolanmış ürünlerde zararlı böceklere yönelik olarak sadece fosfin $\left(\mathrm{PH}_{3}\right)$ ve sülfiril florit (SF) aktif maddeli preparatlar kullanılmaktadır. Fosfin gazı ülkemizde farklı formülasyonlar halinde uzun süreden beri kullanılmakta olan ve ilk kez 1972 yılında tütün, mısır, kuru meyve, hububat ve baklagillerde zararlı organizmalar için ruhsatlandırılmış ve halen kullanılmakta olan bir fümiganttır. Fosfin gazına göre oldukça yeni sayılan ve ülkemizde ilk defa 2009 yılında kuru meyvelerde zararlı böcekler için ve boş hacim uygulamalarında ruhsatlandırılan sülfüril florit bir diğer fümiganttır (Anonim, 2019).

Fosfin veya hidrojen fosfid $\left(\mathrm{PH}_{3}\right)$, düşük moleküler ağırıklı (34.04 akb), yüksek buhar basıncına sahip (20 ${ }^{\circ} \mathrm{C} 34.2 \mathrm{~atm}$.), hızlı bir şekilde dağılabilen ve tahıl yığınları, paketlenmiş ürün ve materyallere iyi bir nüfuz kabiliyeti olan, düşük kaynama noktalı $\left(-87.4{ }^{\circ} \mathrm{C}\right.$ ) bir bileşiktir (Bond, 1984). Bu gaz tüketiciye birçok farklı formülasyonda sunulmaktadır. Bu preparatlar doğrudan gaz formundaki formülasyonlar (ECO ${ }_{2} \mathrm{FUME}, \mathrm{VAPORPH} \mathrm{OSS}_{3}$ ) halinde kullanılabildiği gibi, fosfin gazı metal fosfitler şeklinde (Alüminyum fosfit, magnezyum fosfit, çinko fosfür) bir tablet, pellet, granül ya da toz preparat haline getirilerek de tüketiciye sunulmaktadır. Alüminyum fosfit yaklaşık 3 g'lık pelletler halinde ticari preparat olarak satılmakta ve atmosferik nem ya da mide de bulunan hidroklorik asit ile karşılaşınca içeriğinde toksik olan fosfin gazı açığa çıkmaktadır (Gurjar et al., 2011). Açığa çıkan gaz renksiz olup böcekler bulundukları ortamda solunuma devam ettikleri sürece stigmaları vasıtası ile vücuda giriş yapmakta ve mitokondrilerdeki sitokrom-c oksidaz enzimini inhibe ederek ölüme yol açmaktadır (Price, 1985).

Metalik fosfitlerin belirli sıcaklık ve nem değerlerinde bulunduğu ortamda fosfin gazı salınımı yaptığı bilinmektedir (Banks, 1991; Chadda, 2016 ). Ancak düşük sıcaklık koşullarında fosfin gazının böcekler üzerindeki etkisi net olarak ortaya konulmamıştır. Bu çalışma ile fosfin gazının belirli düşük sıcaklıklarda depolanmış ürün zararlısı olan pirinç biti, kırma biti ve un biti erginlerine karşı toksik etkisi araştırılmıştır. Çalışmalar 2019 yılı Zirai Mücadele Merkez Araştırma Enstitüsü Depolanmış Ürün Zararlıları laboratuvarında yürütülmüştür. 


\section{Materyal ve Metot}

\section{Test böceklerinin yetiştirilmesi}

Denemelerde kullanılan Sitophilus oryzae, Tribolium castaneum ve $T$. confusum Zirai Mücadele Merkez Araştırma Enstitüsü Müdürlüğü, Depolanmış Ürün Zararlıları laboratuvarında bulunan kültürlerden elde edilmiştir. Tribolium castaneum ve $T$. confusum yetiştirilmesinde buğday kırması kullanılmıştır. Bu amaçla yumuşak beyaz ekmeklik buğday, Haseki Yk-99 model yem kırma makinesinde öğütülmüş ve elde edilen kırılmış buğdaya \% 5 oranında kuru maya eklenerek [Saccaromyces cerevisiae Meyen ex Hansen (Saccharomycetales:

Saccharomycetaceae)] böceklerin sağlıklı bir şekilde çoğalabilmesi için kültür besini elde edilmiştir. Sitophilus oryzae üretiminde ise sağlam yumuşak beyaz ekmeklik buğday kullanılmıştır. Böcekler, ağızları tül ile kapatılmış bir litre hacimli kavanozlarda $25{ }^{\circ} \mathrm{C}$ sıcaklık ve $\% 65 \pm 5$ orantılı neme sahip böcek yetiştirme odasında yetiştirilmiştir (Ertürk ve ark., 2017). Ergin böceklerde cinsiyet ayırımı yapılmamış bir-dört hafta yaşlı bireyler kullanılmıştır. Bu böcekler $20 \mathrm{ml}$ hacimli PVC'den yapılmış, içerisinde besin bulunan, ağzı kapalı ve fakat fümigantın girişine izin verecek, böceğin kaçışını engelleyecek şekilde üzerinde $1 \mathrm{~mm}$ çapında delikler açılmış olan test kaplarına yerleştirilmiştir.

\section{Fosfin gazının eldesi}

Fosfin gazı, \% 5 sülfürik asit çözeltisi içinde süspanse edilmiş \% 57'lik ticari alüminyum fosfin tablet formülasyonu kullanılarak bir gaz büretinden elde edilmiştir (FAO, 1975). Fosfin gazı Hamilton marka gaz geçirmez şırınga (1 ve $5 \mathrm{ml}$ ) vasıtası ile gaz büretinden çekilerek özel olarak hazırlanmış $3 \mathrm{~L}$ hacimli, test kapları içerisinde ergin böceklerin bulunduğu, gaz geçirmez fümigasyon birimlerinin üzerinde bulunan bir septumdan enjekte edilmiştir (Şekil 1).

\section{Fümigant aktivite çalışmaları}

Denemeler $1{ }^{\circ} \mathrm{C}$ ve $2.5^{\circ} \mathrm{C}$ sıcaklık; 4, 9 ve 24 saat uygulama süresi ve koşullarında yürütülmüştür.
Düşük sıcaklık eldesi için Öztiryakiler marka GN 2/1 tip buzdolabı kullanılmış, Onset HOBO UX100 model veri toplayıcı ile sıcaklık ölçümleri takip edilmiştir. Fosfin gazı konsantrasyon ölçümleri için Uniphos Fumisense Pro marka elektrokimyasal sensörlü ölçüm cihazı kullanılmıştır. Olası kaçakların tespiti amacıyla Dräger $\mathrm{Pac}^{\circledR} 7000$ gaz detektörü kullanılmıştır. Yapılan çalışmalarda $T$. castaneum, T. confusum ve S. oryzae' de 150, 300 ve $600 \mathrm{ppm}$ fosfin gaz konsantrasyonları denemeye alınmıştır. Denemeler tesadüf parselleri deneme desenine göre 5 tekerrürlü olarak kurulmuş ve her bir tekerrürde 20 adet ergin birey kullanılmıştır. Kontrol grubunda herhangi bir uygulama yapılmamıştır. Fümigant uygulaması yapıldıktan hemen sonra, fümigasyon birimleri düşük sıcaklık şartlarına alınmıştır. Fümigasyon etkisinin belirlenmesi amacıyla böcekler uygulamanın ardından $25{ }^{\circ} \mathrm{C}$ sıcaklık ve \% $65 \pm 5$ orantılı nem ve karanlık koşuldaki böcek yetiştirme odasında 24 saat bekletildikten sonra ölü ve canlı böcek sayımı yapılmıştır.

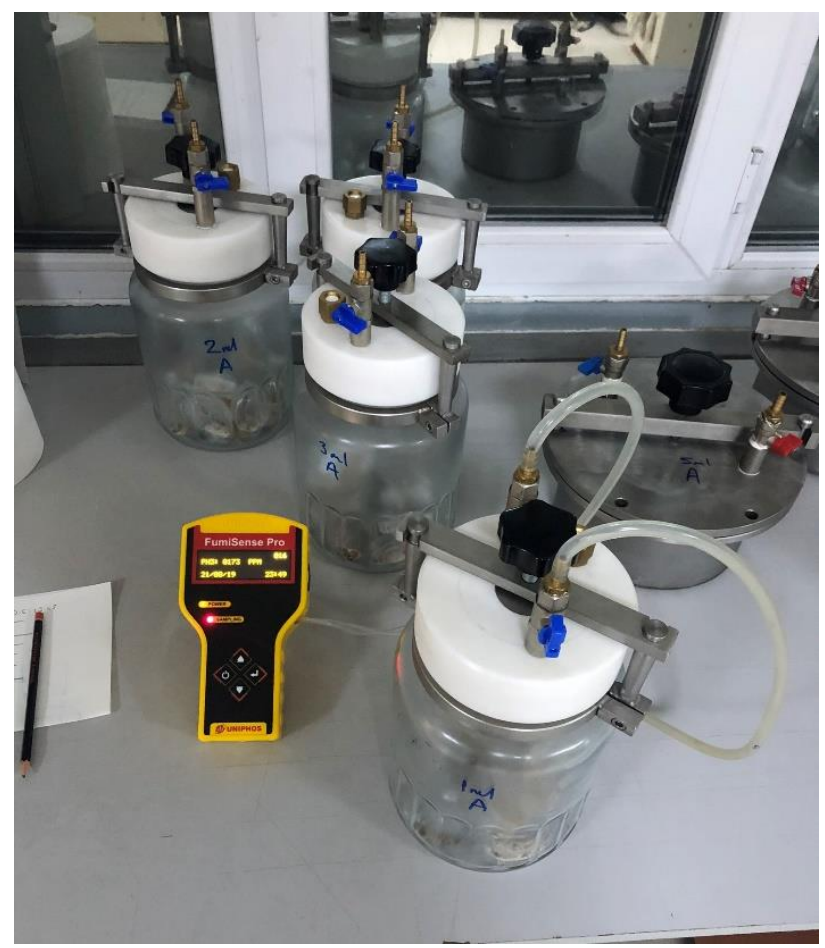

Şekil 1. Çalışmalarda kullanılan $3 \mathrm{~L}$ hacimli fümigasyon birimleri ve fosfin gazı ölçüm cihazı

Figure 1. 3 L volume fumigation units and phosphine gas measuring device used in the studies

\section{Istatistiki analizler}

Fosfin gazı uygulamalarından elde edilen sonuçlar önce yüzde ölüm değerlerine çevrilmiş 
daha sonra Arcsin transformasyonuna tabi tutulmuştur. $\mathrm{Bu}$ veriler ile varyans analizi yapılmıştır. Ayrıca uygulamalar arasındaki farklılıklar Tukey çoklu karşılaştırma ortaya konmuştur. Analizler MINITAB Release 18 programı yardımıyla yürütülmüştür.

\section{Araştırma Bulguları ve Tartışma}

Fosfin gazının düşük sıcaklık koşullarında $T$. castaneum, $T$. confusum ve $S$. oryzae'deki toksik etkilerinin araştırıldığı bu çalışmada her üç tür için farklı ölüm oranları elde edilmiştir. T. castaneum için en düşük ölüm oranı dört saatlik uygulama süresi bakımından 150 ppm dozunda \% 61.06'lık ölüm oranı elde edilirken bu oran aynı süre ve doz koşullarında $2.5^{\circ} \mathrm{C}$ sıcaklıkta \% 98.18 olarak tespit edilmiştir. 24 saatlik uygulama süresi ve $2.5^{\circ} \mathrm{C}$ sıcaklıkta ise çalışılan bütün dozlarda \% 100 ölüm elde edilmiştir 300 ppm dozda en düşük ölüm oranı dokuz saatlik uygulama süresi ve $1{ }^{\circ} \mathrm{C}$ 'lik sıcaklık koşularında \% 98.81 olarak belirlenmiş ve bu ölüm oranını aynı sıcaklık koşulunda 4 saatlik uygulama süresinde \% 99.80'lik ölüm oranı izlemiştir. 600 ppm dozunda $2.5{ }^{\circ} \mathrm{C}$ sıcaklıkta \% 99.80'lik ölüm oranı, 9 saatlik uygulama süresinde elde edilmiştir (Çizelge 1).

Çizelge 1. Fosfin gazının farklı sıcaklık, süre ve uygulama dozlarının Tribolium castaneum'a karşı toksisitesi Table 1. Toxicity of phosphine gas to Tribolium castaneum at different temperatures, time and application doses

\begin{tabular}{|c|c|c|c|c|c|c|}
\hline \multirow{3}{*}{$\begin{array}{l}\text { Doz } \\
\text { Dosage } \\
\text { (ppm) }\end{array}$} & \multicolumn{6}{|c|}{$\begin{array}{c}\% \text { Ölüm } \pm \text { SE } \\
\text { Mortality } \% \pm S E\end{array}$} \\
\hline & \multicolumn{2}{|c|}{$\begin{array}{l}4 \text { saat } \\
4 \text { hours }\end{array}$} & \multicolumn{2}{|c|}{$\begin{array}{l}9 \text { saat } \\
9 \text { hours }\end{array}$} & \multicolumn{2}{|c|}{$\begin{array}{l}24 \text { saat } \\
24 \text { hours }\end{array}$} \\
\hline & $1{ }^{\circ} \mathrm{C}$ & $2.5^{\circ} \mathrm{C}$ & $1{ }^{\circ} \mathrm{C}$ & $2.5^{\circ} \mathrm{C}$ & $1{ }^{\circ} \mathrm{C}$ & $2.5^{\circ} \mathrm{C}$ \\
\hline 150 & $61.06 \pm 0.2 b^{1}$ & $98.18 \pm 0.68 b$ & $96.47 \pm 1.48 a$ & $99.80 \pm 0.45 a$ & $99.80 \pm 0.45 a$ & $100.00 \pm 0 a$ \\
\hline 300 & $99.80 \pm 0.45 a$ & $100.00 \pm 0 a$ & $98.81 \pm 1.05 a$ & 100.00土0.a & $100.00 \pm 0 a$ & $100.00 \pm 0 a$ \\
\hline 600 & $100.00 \pm 0 a$ & $100.00 \pm 0 a$ & $100.00 \pm 0 a$ & $99.80 \pm 0.45 a$ & $100.00 \pm 0 a$ & $100.00 \pm 0 a$ \\
\hline $\begin{array}{l}\text { Kontrol } \\
\text { Control }\end{array}$ & $0.20 \pm 0.45 c$ & $0.00 \pm 0 c$ & $0.00 \pm 0 b$ & $0.00 \pm 0 b$ & $0.41 \pm 0.92 b$ & $0.00 \pm 0 b$ \\
\hline
\end{tabular}

${ }^{1}$ Aynı sütunu takip eden farklı harfler arasında istatistiki anlamda fark vardır (Anova, $\mathrm{P}<0.05$. Tukey test).

Different letters in the same row indicate that the differences between the means are significant (Anova, $P<0.05$. Tukey test)

SE: Standart hata

SE: Standard error

Tribolium confusum için yapılan çalışmalarda ise en düşük \% 78.15'lik ölüm oranı ile 150 ppm dozunda, $1{ }^{\circ} \mathrm{C}$ sıcaklık ve 4 saatlik uygulama süresi sonunda elde edilmiştir. Aynı koşullar altında $2.5{ }^{\circ} \mathrm{C}$ derece sıcaklıktaki ölüm oranı \% 97.63 olarak belirlenmiştir. Buna benzer bir durum dokuz saatlik uygulama süresinde de görülmüş ve ölüm oranları 150 ppm dozda 1 ve $2.5^{\circ} \mathrm{C}$ derecelik sıcaklıklar için sırasıyla \% 94.62 ve \% 99.19 olarak tespit edilmiştir.
24 saatlik uygulama süresi 1 ve $2.5{ }^{\circ} \mathrm{C}$ derecelik sıcaklıklar ve bütün dozlarda mutlak ölüm görülmüştür. $300 \mathrm{ppm}$ doz çalışmalarında $1{ }^{\circ} \mathrm{C}$ sıcaklıkta 4 ve 9 saatlik uygulama sürelerinde $\%$ 99.19'luk ölüm elde edilmiştir. 600 ppm doz uygulamalarında ise sadece $2.5{ }^{\circ} \mathrm{C}$ derecelik sıcaklıkta \% 99.80'lik ölüm oranı elde edilmiş, diğer bütün sıcaklık, zaman ve doz değerlerinde mutlak ölüm görülmüştür (Çizelge 2).

Çizelge 2. Fosfin gazının farklı sıcaklık, süre ve uygulama dozlarının Tribolium confusum'a karşı toksisitesi Table 2. Toxicity of phosphine gas to Tribolium confusum at different temperatures, time and application doses

\begin{tabular}{|c|c|c|c|c|c|c|}
\hline \multirow{3}{*}{$\begin{array}{c}\text { Doz } \\
\text { Dosage } \\
\text { (ppm) }\end{array}$} & \multicolumn{6}{|c|}{$\begin{array}{c}\% \text { Ölüm } \pm S E \\
\text { Mortality } \% \pm S E\end{array}$} \\
\hline & \multicolumn{2}{|c|}{$\begin{array}{l}4 \text { saat } \\
4 \text { hours }\end{array}$} & \multicolumn{2}{|c|}{$\begin{array}{c}9 \text { saat } \\
9 \text { hours }\end{array}$} & \multicolumn{2}{|c|}{$\begin{array}{l}24 \text { saat } \\
24 \text { hours }\end{array}$} \\
\hline & $1{ }^{\circ} \mathrm{C}$ & $2.5^{\circ} \mathrm{C}$ & $1{ }^{\circ} \mathrm{C}$ & $2.5^{\circ} \mathrm{C}$ & $1{ }^{\circ} \mathrm{C}$ & $2.5^{\circ} \mathrm{C}$ \\
\hline 150 & $78.15 \pm 0.14 b^{1}$ & $97.63 \pm 0.95 a$ & $94.62 \pm 0.99 b$ & $99.19 \pm 0.68 a$ & $100.00 \pm 0 a$ & $100.00 \pm 0 a$ \\
\hline 300 & $99.19 \pm 0.68 a$ & $100.00 \pm 0 a$ & $99.19 \pm 0.68 a b$ & $100.00 \pm 0 a$ & $100.00 \pm 0 a$ & $100.00 \pm 0 a$ \\
\hline 600 & $100.00 \pm 0 a$ & $100.00 \pm 0 a$ & $100.00 \pm 0 a$ & $99.80 \pm 0.45 a$ & $100.00 \pm 0 a$ & $100.00 \pm 0 a$ \\
\hline $\begin{array}{l}\text { Kontrol } \\
\text { Control }\end{array}$ & $0.00 \pm 0 c$ & $0.00 \pm 0 b$ & $0.00 \pm 0 c$ & $0.00 \pm 0 b$ & $0.63 \pm 1.4 b$ & $0.63 \pm 1.4 b$ \\
\hline
\end{tabular}

${ }^{1}$ Aynı sütunu takip eden farklı harfler arasında istatistiki anlamda fark vardır (Anova, $\mathrm{P}<0.05$. Tukey test).

Different letters in the same row indicate that the differences between the means are significant (Anova, P<0.05. Tukey test)

SE: Standart hata; SE: Standard error 
Çizelge 3. Fosfin gazının farklı sıcaklık, süre ve uygulama dozlarının Sitophilus oryzae'ye karşı toksisitesi Table 3. Toxicity of phosphine gas to Sitophilus oryzae at different temperatures, time and application doses

\begin{tabular}{|c|c|c|c|c|c|c|}
\hline \multirow{3}{*}{$\begin{array}{c}\text { Doz } \\
\text { Dosage } \\
\text { (ppm) }\end{array}$} & \multicolumn{6}{|c|}{$\begin{array}{c}\% \text { Ölüm } \pm S E \\
\text { Mortality } \% \pm S E\end{array}$} \\
\hline & \multicolumn{2}{|c|}{$\begin{array}{l}4 \text { saat } \\
4 \text { hours }\end{array}$} & \multicolumn{2}{|c|}{$\begin{array}{l}9 \text { saat } \\
9 \text { hours }\end{array}$} & \multicolumn{2}{|c|}{$\begin{array}{l}24 \text { saat } \\
24 \text { hours }\end{array}$} \\
\hline & $1{ }^{\circ} \mathrm{C}$ & $2.5^{\circ} \mathrm{C}$ & $1{ }^{\circ} \mathrm{C}$ & $2.5^{\circ} \mathrm{C}$ & $1{ }^{\circ} \mathrm{C}$ & $2.5^{\circ} \mathrm{C}$ \\
\hline 150 & $0.20 \pm 0.45^{1}$ & $90.34 \pm 1.49 b$ & $100.00 \pm 0 a$ & $100.00 \pm 0 a$ & $100.00 \pm 0 a$ & $100.00 \pm 0 a$ \\
\hline 300 & $100.00 \pm 0 a$ & $97.63 \pm 0.95 a b$ & $100.00 \pm 0 a$ & $100.00 \pm 0 a$ & $100.00 \pm 0 a$ & $100.00 \pm 0 a$ \\
\hline 600 & $98.18 \pm 0.68 a$ & $99.80 \pm 0.45 a$ & $100.00 \pm 0 a$ & $100.00 \pm 0 a$ & $100.00 \pm 0 a$ & $100.00 \pm 0 a$ \\
\hline $\begin{array}{l}\text { Kontrol } \\
\text { Control }\end{array}$ & $0.00 \pm 0 b$ & $0.20 \pm 0.45 c$ & $7.93 \pm 0.06 b$ & $0.00 \pm 0 b$ & $6.85 \pm 0.17 b$ & $0.00 \pm 0 b$ \\
\hline
\end{tabular}

${ }^{1}$ Aynı sütunu takip eden farklı harfler arasında istatistiki anlamda fark vardır (Anova, $\mathrm{P}<0.05$. Tukey test).

Different letters in the same row indicate that the differences between the means are significant (Anova, P<0.05. Tukey test)

SE: Standart hata

SE: Standard error

Çizelge 4. Tribolium castaneum, Tribolium confusum ve Sitophilus oryzae ölümü üzerine böcek türü, sıcaklık, zaman ve doz interaksiyonlarına ait varyans analiz tablosu

Table 4. Analysis of variance of insect species, temperature, time and dose interactions on the mortality of Tribolium castaneum, Tribolium confusum and Sitophilus oryzae

\begin{tabular}{|c|c|c|c|}
\hline $\begin{array}{l}\text { Faktör } \\
\text { Source }\end{array}$ & Df & $\mathrm{F}$ & $P$ \\
\hline $\begin{array}{l}\text { Böcek } \\
\text { Insect }\end{array}$ & 2 & 0.20 & 0.820 \\
\hline $\begin{array}{l}\text { Doz } \\
\text { Dosage }\end{array}$ & 3 & 7802.76 & 0.000 \\
\hline $\begin{array}{l}\text { Zaman } \\
\text { Time }\end{array}$ & 2 & 187.14 & 0.000 \\
\hline $\begin{array}{l}\text { Sıcaklık } \\
\text { Temperature }\end{array}$ & 1 & 27.63 & 0.000 \\
\hline $\begin{array}{l}\text { Böcek*doz } \\
\text { Insect*dosage }\end{array}$ & 6 & 24.25 & 0.000 \\
\hline $\begin{array}{l}\text { Böcek*zaman } \\
\text { Insect*time }\end{array}$ & 4 & 50.67 & 0.000 \\
\hline $\begin{array}{l}\text { Böcek*sıcaklık } \\
\text { Insect*temperature }\end{array}$ & 2 & 2.90 & 0.057 \\
\hline $\begin{array}{l}\text { Doz*zaman } \\
\text { Dosage*time }\end{array}$ & 6 & 89.74 & 0.000 \\
\hline $\begin{array}{l}\text { Doz*sıcaklık } \\
\text { Dosage* temperature }\end{array}$ & 3 & 101.68 & 0.000 \\
\hline $\begin{array}{l}\text { Zaman*sıcaklık } \\
\text { Time* temperature }\end{array}$ & 2 & 74.84 & 0.000 \\
\hline $\begin{array}{l}\text { Böcek*doz*zaman } \\
\text { Insect*dosage*time }\end{array}$ & 12 & 14.12 & 0.000 \\
\hline $\begin{array}{l}\text { Böcek*doz*sıcaklık } \\
\text { Insect*dosage*temperature }\end{array}$ & 6 & 20.70 & 0.000 \\
\hline $\begin{array}{l}\text { Böcek*zaman*sıcaklık } \\
\text { Insect*time*temperature }\end{array}$ & 4 & 20.48 & 0.000 \\
\hline $\begin{array}{l}\text { Doz*zaman*sıcaklık } \\
\text { Dosage*time*temperature }\end{array}$ & 6 & 39.85 & 0.000 \\
\hline $\begin{array}{l}\text { Böcek*doz*zaman*sıcaklık } \\
\text { Insect*dosage*time*temperature }\end{array}$ & 12 & 11.16 & 0.000 \\
\hline $\begin{array}{l}\text { Hata } \\
\text { Error }\end{array}$ & 288 & & \\
\hline $\begin{array}{l}\text { Genel Toplam } \\
\text { Total }\end{array}$ & 359 & & \\
\hline
\end{tabular}

Sitophilus oryzae en düşük ölüm $1{ }^{\circ} \mathrm{C}$ derecelik sıcaklık koşullarında, 4 saatlik uygulama süresi ve
150 ppm dozda \% 0.20'lik ölüm oranı ile kontrol grubuyla aynı grupta yer almıştır. Sıcaklığın 
artmasıyla beraber ölüm oranı \% 90.34 olarak belirlenmiş ve farklı bir istatistik grupta yer almıştır. Mutlak ölüm açısından, diğer iki türden farklı şekilde 9 ve 24 saatlik uygulama süresi ve 1 ve $2.5^{\circ} \mathrm{C}$ derece sıcaklık koşullarındaki bütün dozlarda \% 100 ölüm meydana gelmiştir. 300 ppm doz uygulaması ve 2.5 ${ }^{\circ} \mathrm{C}$ derece sıcaklık koşulunda 4 saatlik maruziyet sonunda \% 97.63'lük ölüm oranı elde edilirken, çalışılan diğer bütün doz, zaman ve sıcaklıklarda \% 100'lük görülmüştür. Buna karşın 600 ppm dozda 1 ve $2.5{ }^{\circ} \mathrm{C}$ derece sıcaklık koşulları ve 4 saatlik uygulama süresi sonunda ölüm oranları sırası ile \% 98.18 ve \% 99.80olarak belirlenmiştir. Diğer doz, sıcaklık ve zaman koşullarında \%100'lük mutlak ölüm elde edilmiştir (Çizelge 3).

Tribolium castaneum, $T$. confusum ve $S$. oryzae 'nin böcek*doz*zaman*sıcaklık faktörleri bakımından varyans analiz tablosu incelendiğinde önemli derecede interaksiyon $(F=11,6 ; P<0,05)$ olduğu belirlenmiştir (Çizelge 4).

Depolanmış ürün zararlısı böceklerin büyük çoğunluğu tropik ya da subtropikal alanlardan dünyaya yayılmışlardır. Ancak bu böcekler düşük sıcaklıkların görüldüğü alanlarda da yayılma eğilimi göstermektedirler. Depolanmış ürün zararlısı böceklerin yaşaması için en ideal sıcaklık ve nem değerleri $25-32{ }^{\circ} \mathrm{C}$ derece sıcaklık ve \% 65-75 oransal nemdir (Howe, 1965; Fields, 1992). Depolanmış ürün zararlısı böceklere karşı düşük sıcaklık koşullarının ( $3{ }^{\circ} \mathrm{C}$ 'den $-18^{\circ} \mathrm{C}$ 'ye) böceklerin hareketinde yavaşlama, hareketin durması, haftalara yayılan ve ölümle sonuçlanan bir zararının olduğu ortaya konmuştur (Fields and White 2002; Adler 2010). Benzer şekilde bu çalışma yapılan diğer çalışmalara paralel şekilde sonuçlanmış, 1 ve $2.5{ }^{\circ} \mathrm{C}$ derecelik sıcaklık uygulamalarının özellikle kontrol grubundaki test böceklerinde geçici hareketsizliği sebep olduğu görülmüştür. Elde edilen bulgular bakımından varyans analiz tablosunda böcek türleri arasında önemli bir interaksiyon çıkmamasına rağmen, Madrid et al., (1990) yapmış oldukları çalışmada düşük sıcaklığa karşı en dayanıklı türün $T$. castaneum olduğunu bildirmişlerdir.

Bond (1984), böceklerle mücadelede kullanılan fümigantların en yüksek insektisidal etkiyi göstermesi için gereken sıcaklıkların 10-35 ${ }^{\circ} \mathrm{C}$ derece sıcaklık arasında değiştiğini ve sıcaklık artışının fümigasyon işlemini olumlu yönde etkilediğini bildirmiştir. Aulicky et al., (2015) 19.6$20.4^{\circ} \mathrm{C}$ arasında değişen sıcaklıklarda $T$. confusum'un yumurta dönemine karşı yapılan değirmen fümigasyonunda mutlak ölüm elde edememişlerdir. Her ne kadar bu çalışmada $T$. confusum'un yumurta dönemi çalışılmamış olsa da bulgular göstermektedir ki belirli süre, doz ve sıcaklıklarda ergin bireylere karşı çok düşük sıcaklık ve boş hacim fümigasyonunda \% 100 ölüm elde edilmiştir.

Düşük sıcaklılarda böceklerde görülen metabolizma hızının yavaşlaması ve buna bağlı olarak solunumun azalması sonucu fosfin toksisitesinin doğrudan etkilendiği genel olarak kabul edilmektedir (Cotton, 1932; Evans, 1980). Böceklerin gelişme döneminin erken evrelerinde görülen fosfin gazına karşı daha dayanıklı kabul edilirken, ileri dönemlerde bu dayanıklılığın azaldığı bilinmektedir (Howe, 1974; Bell, 1976; Hole et al., 1976). Bu denemede çalışılan her üç böcek türünün ergin evreleri kullanılmış olup, ergin evrenin fosfine karşı daha hassas olduğu düşünülmektedir.

Böceklerde $\mathrm{PH}_{3}$ toksisitesi, çevre sıcaklından etkilenmekte olup bu çalışmada da görüleceği üzere sıcaklık artışı $\mathrm{PH}_{3}$ 'ün fümigant aktivitesini artırmıştır. Kyung et al., (2018) Frankliniella occidentalis (Thysanoptera: Thripidae)'in yumurta dönemine karşı yapmış oldukları çalışmada $\mathrm{LT}_{99}$ değerinin $2{ }^{\circ} \mathrm{C}$ ve $5{ }^{\circ} \mathrm{C}$ derece sıcaklıkta, 24 saatlik uygulama süresi sonunda sırasıyla 98.17 ve $64.69 \mathrm{mg} \cdot \mathrm{h} \mathrm{L}^{-1}$ olduğunu bildirmişlerdir.

Genel bir uygulama pratiği olarak çevre sıcaklığının $10{ }^{\circ} \mathrm{C}$ altına düşmesi sonucunda fümigantlar ile böcekleri öldürmek gittikçe zorlaşmaktadır. Ancak özellikle düşük sıcaklıkta fosfin gazı uygulamasının taze meyve, sebze ve kesme çiçeklerde görülen fitotoksisiteyi azaltmasının yanı sıra $0-15{ }^{\circ} \mathrm{C}$ sıcaklık değerleri arasında yapılan fosfin gazı uygulamasının, Tetranychus urticae Koch, Pseudococcus longispinus, Frankliniella occidentalis, Cydia 
pomonella, Carposina niponensis ve Bactrocera correcta (Bezzi) gibi çeşitli zararlılar üzerinde etkili olduğu bildirilmiştir (Horn and Horn 2004; Horn et al., 2005; Liu 2008; Bo et al., 2010; Jamieson et al., 2012; Zhang et al., 2012; Rogers et al. 2013; Liu et al., 2015). Yapılan bu çalışma sonucu elde edilen veriler araştırıcıların yapmış oldukları çalışmalara benzerlik göstermiştir. Ayrıca düşük sıcaklıklarda fümigantın penetrasyon kabiliyetini etkileyen absorpsiyon en önemli fiziksel faktördür (Bond, 1984). Bu çalışmada her ne kadar fümigant absorpsiyonuna yönelik bir veri üretilmemiş olsa da, uygulanan sıcaklıklar özellikle ürün absorpsiyonu göz ardı edildiğinde düşük sıcaklıklarda da çalışılan türler yönüyle etkili sonuçlar alınacağı ortaya konmuştur. Ayrıca düşük sıcaklık altında dormant haldeki tohum ve bitki kısımlarına $\mathrm{PH}_{3}$ fümigasyonu yapılacaksa, bu ürünler üzerinde yüksek sıcaklığın getirmiş olduğu fizyolojik mekanizmaların olası uyarıcı etkisinden kaçınılarak muhtemel fitotoksisiden kaçınılabileceği de düşünülmektedir.

\section{Sonuçlar}

Depolanmış ürün zararlılarına fümigasyon amacı ile kullanılan fümigantlar içerisinde fosfin gazı ülkemizde ve dünya sıklıkla başvurulan bir kimyasaldır. Bu kimyasalın metalik fosfit formülasyonları (alüminyum fosfit, magnezyum fosfit vb.) belirli sıcaklık ve sürelerde hava nemi ile tepkimeye girerek öldürücü etkiye sahip olan fosfin gazının açığa çıkmasına neden olur. Bu çalışma ile fosfin gazının FAO metodu kullanılarak elde edilmesi ve düşük sıcaklık ve belirli süreli maruziyetinin Pirinç biti, Kırma ve Un bitlerinin ergin dönemlerine karşı toksik etkisi ortaya konmuştur. Bu çalışmanın sonuçlarından elde edilen veriler göstermiştir ki gelecek araştırmalar için düşük sıcaklık çalışmalarının sadece ergin dönem için değil, böceklerin diğer biyolojik dönemlerinin de çalışılması ve etkisinin ortaya konması gerekmektedir. Ayrıca uluslararası ticarete konu olan tarımsal ürünlerin ilgili ülkenin bitki sağlığı gerekliliklerine -özellikle fümigasyon açısından- uygun şekilde yapılabilmesi süre, sıcaklık ve doz gibi faktörlerin belirlenmesi, sadece boş hacim fümigasyonuna yönelik değil aynı zamanda uygulama yapılan ürünlere yönelik olarak fitotoksisite ve kalite parametrelerine olan etkilerinin de araştırılmasının uygun olacağı düşünülmektedir.

Çıkar Çatışması Beyanı: Makale yazarları aralarında herhangi bir çıkar çatışması olmadığını beyan eder.

\section{Kaynaklar}

Anonim, (2019). Bitki koruma ürünleri veri tabanı, https://bku.tarim.gov.tr/Arama/Index. (Erişim tarihi:16.12.2019).

Anonymous, (1998). Methyl Bromide Technical Options Committee, Assessment of Alternatives to Methyl Bromide. United Nations Environmental Programme, Ozone Secretariat. Nairobi, Kenya, 374 pp.

TEAP, (2000). Montreal Protocol on substances that deplete the ozone layer: United Nations Environmental Programme Technology and Economic Assessment Panel. April 2000 Rep. United Nations.

Aulicky, R., Stejskal, V., Frydova, B., ve Athanassiou, C. G. (2015). Susceptibility of two strains of the confused flour beetle (Coleoptera: Tenebrionidae) following phosphine structural mill fumigation: effects of concentration, temperature, and flour deposits. Journal of Economic Entomology, 108(6), 2823-2830.

Banks, H. J. (1991). Influence of water and temperature on release of phosphine from aluminium phosphidecontaining formulations. Journal of Stored Products Research, 27(1), 41-56.

Bell, C. H., Price, N., \& Chakrabarti, B. (1996). The methyl bromide issue. John Wiley and Sons. New York, NY.

Bell, C. H. (1976). The tolerance of developmental stages of four stored product moths to phosphine. Journal of Stored Products Research, 12(2), 77-86.

Bond, E. J. (1984). Manual of Fumigation for Insect Control; FAO Plant Production and Protection Paper 54; Food and Agriculture Organization of the United Nations: Rome, Italy.

Chadda, I. C. (2016). Fumigation with phosphine-a perspective. Indian Journal of Entomology, 78(special), 39-44.

Cotton, R. T. (1932). The relation of respiratory metabolism of insects to their susceptibility to fumigants. Journal of Economic Entomology, 25(5), 1088-1103.

Ertürk, S., Yılmaz, A., Fırat, T. A., ve Alkan, M. (2017). Transanethole ve karbondioksit karışımının Rhyzopertha dominica, Tribolium castaneum ve Sitophilus oryzae'ye karşı fümigant etkisi. Bitki Koruma Bülteni, 57(3), 391-400.

Evans, D. E. (1980). Further studies on acclimatization to low temperatures in the grain weevils Sitophilus oryzae (L.) and Sitophilus granarius (L.). Australian Journal of 
Ecology, 5(4), 371-378.

Fields, P. G. (1992). The control of stored-product insects and mites with extreme temperatures. Journal of Stored Products Research, 28(2), 89-118.

Fields, P. G., ve White, N. D. (2002). Alternatives to methyl bromide treatments for stored-product and quarantine insects. Annual Review of Entomology, 47(1), 331-359.

FAO, (1975). Recommended methods for the detection and measurement of resistance of agricultural pests to pesticides-Tentative method for adults of some major pest species of stored cereals, with methyl bromide and phosphine. FAO Method No. 16. FAO Plant Protection Bulletin, 23, 12-25.

Gurjar, M., Baronia, A. K., Azim, A., ve Sharma, K. (2011). Managing aluminum phosphide poisonings. Journal of Emergencies, Trauma and Shock, 4(3), 378-384.

Hole, B. D., Bell, C. H., Mills, K. A., ve Goodship, G. (1976). The toxicity of phosphine to all developmental stages of thirteen species of stored product beetles. Journal of Stored Products Research, 12(4), 235-244.

Horn, F., ve Horn, P. (2004). Fresh fruit fumigation with phosphine as alternative for methyl bromide. In Proceedings of 2004 Annual Research Conference on Methyl Bromide Alternatives and Emissions Reductions (Vol. 31).

Horn, F., Horn, P., ve Sullivan, J. (2005). Current practice in fresh fruit fumigation with phosphine in Chile. In Proceedings of 2005 Annual Research Conference on Methyl Bromide Alternatives and Emissions Reductions (Vol. 31).

Howe, R. W. (1965). A summary of estimates of optimal and minimal conditions for population increase of some stored products insects. Journal of Stored Products Research, 1(2), 177-184.

Howe, R. W. (1974). Problems in the laboratory investigation of the toxicity of phosphine to stored product insects. Journal of Stored Products Research, 10(3-4), 167-181.

Jamieson, L. E., Page-Weir, N. E. M., Chhagan, A., Brash, D. W., Klementz, D., Bycroft, B. L., ... ve Woolf, A. B. (2012). Phosphine fumigation to disinfest kiwifruit. New Zealand Plant Protection, 65, 35-43.

Khare, B. P. (1994). Pests of stored grain and their management. Kalyani Publishers, New Delhi. 304 pp.

Kyung, Y., Kim, H. K., Lee, J. S., Kim, B. S., Yang, J. O., Lee, B. H., ... ve Kim, G. H. (2018). Efficacy and phytotoxicity of phosphine as fumigants for Frankliniella occidentalis (Thysanoptera: Thripidae) on asparagus. Journal of Economic Entomology, 111(6), 2644-2651.

Bo, L., Fanhua, Z., ve Yuejin, W. (2010). Toxicity of phosphine to Carposina niponensis (Lepidoptera: Carposinadae) at low temperature. Journal of Economic Entomology, 103(6), 1988-1993.

Liu, Y. B. (2008). Low temperature phosphine fumigation for postharvest control of western flower thrips (Thysanoptera: Thripidae) on lettuce, broccoli, asparagus, and strawberry. Journal of Economic Entomology, 101(6), 1786-1791.

Madrid, F. J., White, N. D. G., ve Loschiavo, S. R. (1990). Insects in stored cereals, and their association with farming practices in southern Manitoba. The Canadian Entomologist, 122(3), 515-523.

Price, N. R. (1985). The mode of action of fumigants. Journal of Stored Products Research, 21(4), 157-164.

Sallam, M. N. (2013). Insect damage: damage on postharvest. Food and Agriculture Organization of the United Nations. Available online at: http://www. fao. org/fileadmin/user_upload/inpho/docs/Post_Harvest _Compe ndium_-_Pests-Insects. pdf. 